\title{
Correction to: Regional and Species Variations in Spring and Autumn Phenology of 25 Temperate Species in South Korea
}

\author{
Jongho Kim ${ }^{1}$. Sujong Jeong ${ }^{1} \cdot$ Chang-Eui Park ${ }^{2} \cdot$ Hoonyoung Park ${ }^{2} \cdot$ Sungwon Son ${ }^{3} \cdot$ Sang Yong Kim ${ }^{3}$
}

Published online: 2 February 2022

(c) The Author(s) under exclusive licence to Korean Meteorological Society and Springer Nature B.V. 2022

\section{Correction to: Asia-Pacific J Atmos Sci https://doi.org/10.1007/s13143-021-00247-0}

Due to an unfortunate oversight the grant number in the acknowledgment section has been given erroneously. It should read:

This work is supported by the Korea Agency for Infrastructure Technology Advancement (KAIA) grant funded by the Ministry of Land, Infrastructure and Transport (Grant 21UMRG-B158194-02).

The original article has been corrected

Publisher's Note Springer Nature remains neutral with regard to jurisdictional claims in published maps and institutional affiliations.

The original article can be found online at https://doi.org/10.1007/ s13143-021-00247-0.

Sujong Jeong

sujong@snu.ac.kr

1 Department of Environmental Planning, Graduate School of Environmental Studies, Seoul National University, Seoul 08826, Korea

2 Environmental Planning Institute, Seoul National University, Seoul 08826, Korea

3 Department of Plant Resources, Korea National Arboretum, Pocheon 12519, Korea 